\title{
Rubeola IgG Antibody Measurement
}

National Cancer Institute

\section{Source}

National Cancer Institute. Rubeola Ig G Antibody Measurement. NCI Thesaurus. Code C112412.

The determination of the amount of Rubeola IgG antibody present in a sample. 